Andrew G. Roth MD, Melissa Wheeler MD, G.W. Stevenson MD, Steven C.Hall MD

\title{
Comparison of a rigid laryngoscope with the ultrathin fibreoptic la- ryngoscope for tracheal intubation in infants
}

The flexible ultrathin fibreoptic laryngoscope allows placement of endotracheal tubes as small as $2.5 \mathrm{~mm}$ internal diameter. The purpose of this study was to document the safety and efficacy of intubation using an ultrathin fibreoptic laryngoscope. Proved safety and efficacy would justify the routine use of fibreoptic laryngoscopy in normal infants to maintain skills needed for management of the difficult infant airway. In this prospective study, 40 infants $<24$ mo of age scheduled for elective surgery were randomly divided into iwo equal groups. After inhalation induction of anaesthesia, in 20 infants the trachea was intubated using direct rigid laryngoscopy, and in 20 using the ultrathin fibreoptic laryngoscope (size $1.8 \mathrm{~mm}$ OD) Olympus LFP. Time to successful intubation was recorded, as well as blood pressure, heart rate, end-tidal $\mathrm{CO}_{2}$ and oxygen saturation. Airway trauma in the operating room, the post-anaesthesia care unit, and on the first postoperative day was recorded. The intubation times using rigid laryngoscopy were less than thase using $f$ breoptic laryngoscopy (13.6 $\pm 0.9 \mathrm{sec}$ (mean \pm SEM) vs 22.8 \pm 1.7 sec; $P<0.01$ ). Oxygen saturation and end-tidal $\mathrm{CO}_{2}$ readings were not different between the two groups. After intubation, blood pressure and heart rate increased equally in both groups, returning to normal within one to two minutes. There was no difference in the airway trauma between groups. We conclude that the ultrathin fibreoptic laryngoscope is a safe

\section{Key words}

ANAESTHESIA: paediatric;

EQUIPMENT: laryngoscope; fibreoptic;

INTUBATION: technique.

From the Department of Anesthesia, Children's Memorial

Hospital, Chicago, Illinois.

Research was performed at the Children's Memorial Hospital, Chicago. Preliminary research results were presented at the American Academy of Pediatrics, Anesthesiology Section, March 1993, Chicago.

Address correspondence to: Dr. Andrew G. Roth, Department of Pediatric Anesthesia, Children's Memorial Hospital, 2300 Children's Plaza, Chicago, Illinois 60614. Accepted for publication 17th June 1994. and effective method for tracheal intubation in infants and may be used routinely in order to maintain fibreoptic airway skills.

Le fibroscope ultrafin flexible à fibres optiques permet de placer des canules endotrachéales de diamètre interne aussi petit que $2,5 \mathrm{~mm}$. Cette étude vise à démontrer la sécurité et l'efficacité de lintubation avec un fibroscope ultrafin. La preuve de sa sécurité et de son efficacité justifierait son utilisation courante chez les enfants normaux pour maintenir la dextérité nécessaire à la prise en charge des cas difficiles. Pour cette étude prospective, 40 enfants de 24 mois ou moins programmés pour une chirurgie réglée sont répartis au hasard en deux groupes égaux. Après une induction par inhalation, chez 20 enfants, la trachée est intubée par laryngoscopie rigide directe, et chez un même nombre, avec le fibroscope ultrafin (diamètre externe $1,8 \mathrm{~mm}$ ) Olympus LFP. Le délai jusqu'à la réussite de lintubation est enregistré, ainsi que la pression artérielle, la fréquence cardiaque, la $\mathrm{CO}_{2}$ télé-expiratoire et la saturation en oxygène. Tout traumatisme aux voies aériennes en salle d'opération, salle de réveil et au premier jour après l'opération est aussi noté. Le temps requis pour l'intubation avec le laryngoscope rigide est moindre qu'avec le fibroscope (13,6 \pm $0.9 \mathrm{sec}$ (moyenne $\pm S E M$ ) vs $22,8 \pm 1,7 \mathrm{sec} ; P<0,01$ ). La saturation en oxygène et le $\mathrm{CO}_{2}$ télé-expiratoire ne diffèrent pas entre les dewx groupes. Après lintubation, la pression artérielle et la fréquence cardiaque augmentent également dans les deux groupes et retournent à la normale en deşà d'une ou deux minutes. Pour les tramatismes, il n'y a pas de différence entre les deux groupes. En conclusion, on peut utiliser le fibroscope avec efficacité et sécurité pour lintubation des enfants et de façon courante pour maintenir son habileté avec ce type dinstrument.

Use of the flexible fibreoptic laryngoscope in airway management of the adult and older paediatric patient is well established. ${ }^{1-3}$ The ultrathin (OD $1.8 \mathrm{~mm}$ ) fibreoptic laryngoscope with directable tip (Olympus LFP, Lake Success, New York 11042) allows placement of endotracheal tubes as small as $2.5 \mathrm{~mm}$ internal diameter (ID) (with 
the $15 \mathrm{~mm}$ adapter removed). As with many learned skills, repeated use may be conducive to improving and maintaining one's ability to use this instrument effectively. This study compares the efficacy and safety of ultrathin fibreoptic laryngoscopy with rigid laryngoscopy for tracheal intubation in healthy infants between 1 and $24 \mathrm{mo}$ of age.

\section{Methods}

After approval of the Institutional Review Board of the Children's Memorial Hospital, informed consent was obtained from parents of 40 infants $<24$ mo of age. All infants were ASA physical status 1 or 2 with no history of chronic airway disease, acute respiratory illness, or serious systemic disease. Each infant was scheduled to undergo elective surgery requiring the placement of an oral endotracheal tube.

Study infants were randomly assigned to two groups of equal size (direct rigid laryngoscopy versus fibreoptic laryngoscopy). ${ }^{4}$ Infants were premedicated ten to fifteen minutes before the induction of anaesthesia with atropine $20 \mu \mathrm{g} \cdot \mathrm{kg}^{-1}$ im and, if $>12 \mathrm{mo}$ of age, with midazolam $100 \mu \mathrm{g} \cdot \mathrm{kg}^{-1} \mathrm{im}$. All infants were monitored with electrocardiogram (ECG), automated blood pressure (BP) cuff, precordial stethoscope, and temperature probe. A Nellcor 1000 (Nellcor Inc., Hayward, CA 94545) was used to measure oxygen saturation $\left(\mathrm{O}_{2}\right.$ SAT) and end tidal $\mathrm{CO}_{2}\left(\mathrm{PETCO}_{2}\right)$. Induction and intubation were performed by one of two attending anesthetists familiar with the use of fibreoptic laryngoscopy in infants. Both had previously gained some proficiency with the Olympus ultrathin fibreoptic scope (approximately 20 previous intubations) in normal and abnormal paediatric airways before this study.

Anaesthesia was induced with halothane $/ 60 \%$ nitrous oxide and $40 \%$ oxygen by mask. The inspired halothane concentration was gradually increased to $3 \%$. An intravenous catheter was placed and either vecuronium or pancuronium $100 \mu \mathrm{g} \cdot \mathrm{kg}^{-1}$ was administered. Nitrous oxide was then discontinued for $60 \mathrm{sec}$, inspired halothane reduced to $1.5 \%$, and ventilation controlled to achieve an $\mathrm{PETCO}_{2}$ concentration in the $29-33 \mathrm{mmHg}$ range.

After muscle relaxation was judged to be adequate by peripheral nerve stimulation, in infants in the rigid laryngoscopy group the tracheas were intubated orally using direct laryngoscopy with a Miller \#1 blade; in infants in the fibreoptic laryngoscopy group intubation was performed orally using the ultrathin fibreoptic laryngoscope (Olympus LFP, Lake Success, New York 11042). Endotracheal tube size was based on age (1-6 mo - size 3.5 $\mathrm{mm} \mathrm{ID,} \mathrm{7-15} \mathrm{mo} \mathrm{-} 4.0 \mathrm{~mm} \mathrm{ID,} \mathrm{16-24} \mathrm{mo} \mathrm{-} 4.5 \mathrm{~mm}$ ID) or history of endotracheal tube size used during a recent anaesthetic, if available. Systolic BP and diastolic
TABLE I Mean ages and weights of study infants

\begin{tabular}{lll}
\hline Group & Age $(\mathrm{mo})$ & $W t(\mathrm{~kg})$ \\
\hline Rigid laryngoscopy & $12.0 \pm 1.4$ & $9.4 \pm 0.6$ \\
Fibreoptic laryngoscopy & $10.7 \pm 1.6$ & $9.0 \pm 0.6$ \\
\hline
\end{tabular}

Mean \pm SEM.

$\mathrm{BP}$, heart rate (HR) and rhythm, PeTCO $\mathrm{CO}_{2}$, and $\mathrm{O}_{2}$ SAT were measured immediately before induction of anaesthesia, prior to laryngoscopy, immediately after intubation, and at one-minute intervals for five minutes following intubation. Time to visualize the vocal cords during rigid laryngoscopy or time to pass the tip of the fibreoptic laryngoscope through the vocal cords during fibreoptic laryngoscopy (time 1), as well as time to successful intubation (time 2) were measured. The number of intubation attempts was recorded. A notation was made if the operator felt that intubation was difficult.

If the operator anticipated that intubation would not be completed within $60 \mathrm{sec}$ or if the $\mathrm{O}_{2}$ SAT decreased to $<98 \%$ for more than five seconds, the intubation attempt was aborted. The lungs were then ventilated by mask with oxygen and halothane before intubation was again attempted. The reason for each intubation failure was determined and recorded. After intubation, the airway pressure at which a leak could first be heard by auscultation was reconded. A blinded observer recorded trauma to lips, gums, and oropharynx in the operating room and at approximately one hour after admission into the post-anaesthesia care unit (PACU). A croup score was recorded in the PACU using a standard croup scoring system. ${ }^{5}$ The infant's family was called on the first postoperative day; any history of swallowing difficulties or coughing or any observed injuries to lips, gums, or teeth were recorded.

Differences in mean values of vital signs between and within groups 1 and 2 were evaluated with repeated measures two-way ANOVA. Weight, age, and time to intubate were analyzed with two-tailed $t$ tests. A $P<0.05$ was considered statistically significant. Changes in vital signs compared with preinduction values were analyzed with a 2-tailed $t$ test with Bonferroni correction. Complication occurrences were evaluated using chi-squared.

\section{Results}

There were no demographic differences between groups (Table I). All rigid laryngoscopy infants had successful tracheal intubation at the first attempt, with a mean time to cord visualization $\left(T_{1}\right)$ of $7.2 \pm 0.5 \mathrm{sec}$ and mean time to complete intubation $\left(T_{2}\right)$ of $13.6 \pm 0.9 \mathrm{sec}$ (Figure). In the fibreoptic group, mean time to pass the fibreoptic scope through the vocal cords $\left(T_{1}\right)$ was $14.5 \pm$ 


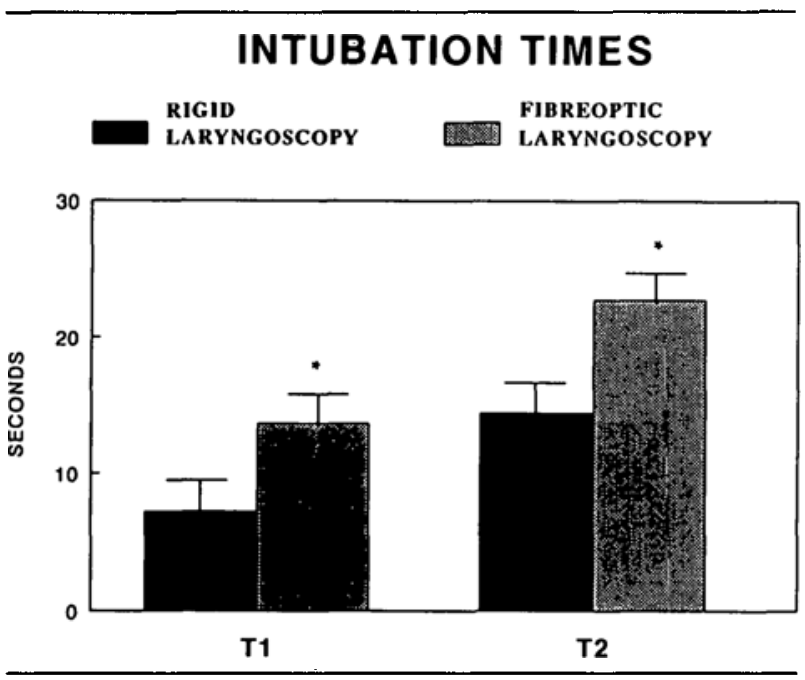

FIGURE Intubation times for rigid laryngoscopy versus fibreoptic laryngoscopy. $T_{1}=$ time to visualize the vocal cords (rigid laryngoscopy group) or time to pass the tip of the fibreoptic laryngoscope through the vocal cords (fibreoptic laryngoscopy group). $T_{2}=$ time to complete the intubation. $* P<0.05$ compared with rigid laryngoscopy group.

$1.65 \mathrm{sec}$ and mean time to successful intubation $\left(\mathrm{T}_{2}\right)$ was $22.8 \pm 1.7 \mathrm{sec}$ (Figure).

Vocal cord visualization was initially difficult in three infants in the fibreoptic laryngoscopy group. The cause of difficulty in one of these infants was light source failure. Repositioning of the mandible resulted in visualization in the other two infants. The second intubation attempt was successful in each of these three cases. Total time for intubation did not exceed $40 \mathrm{sec}$ in any infant. Intubation times were increased in the fibreoptic laryngoscopy group compared with the rigid laryngoscopy group. The oxygen saturation did not decrease to $<99 \%$ in any study infant. The $\mathrm{PETCO}_{2}$ measurements were unchanged pre- and post-intubation, and were equivalent in both study groups (Table II). No intubation was felt to be of great difficulty.

Within each group there were increases in systolic BP, diastolic BP, and HR post-intubation compared with immediately before intubation (Table III); however, there were no differences between groups.

No major intubation-related complications occurred in any study infant. One infant in the rigid laryngoscopy group was noted in the PACU to have stridor (croup score $=1$ of a possible 10 ) not requiring therapy. The follow-up phone interview revealed a history of a "barky cough" in two standard laryngoscopy infants and in two fibreoptic laryngoscopy infants. No therapy was required. The infant observed to have stridor in the PACU did not have a "barky cough" at the time of the postoperative phone interview. There were no differences in the
TABLE II $\mathrm{PETCO}_{2}(\mathrm{mmHg})$ Before and after intubation

\begin{tabular}{lll}
\hline Group & $\begin{array}{l}\text { PETCO }_{2} \\
\text { Pre-intubation }\end{array}$ & $\begin{array}{l}\text { PETCO }_{2} \\
\text { Post-intubation }\end{array}$ \\
\hline Rigid laryngoscopy $(n=20)$ & $32.2 \pm 0.3$ & $34.7 \pm 0.6$ \\
Fibreoptic laryngoscopy $(n=20)$ & $31.9 \pm 0.3$ & $34.7 \pm 0.6$ \\
\hline
\end{tabular}

Mean \pm SEM.

occurrence or type of complications identified at surgery, in the PACU or $24 \mathrm{hr}$ postoperatively between groups.

\section{Discussion}

The use of a flexible fibreoptic scope to aid intubation of the trachea in adults was first described by Murphy in 1967. ${ }^{6}$ A fibreoptic bronchoscope suitable for use in older paediatric patients was developed in the late 1970's (Olympus BF-3C4, Lake Success, New York 11042). Since this scope did not allow passage of endotracheal tubes smaller than $4.5 \mathrm{~mm}$ ID, it could not be used directly for intubation of very young infants. Smaller fibreoptic bronchoscopes were introduced in 1984 (Olympus PF-18, and PF-23, Lake Success, New York 11042) but these bronchoscopes did not have a directable tip, thus limiting use for intubation. ${ }^{7}$ The recent introduction of the ultrathin fibreoptic laryngoscope with directable tip allows tracheal intubation with tubes as small as $\mathbf{2 . 5}$ mm ID.

Tracheal intubation of infants cannot be equated with adult intubation because of multiple anatomical differences, including a more cephalad larynx and a more angulated, long, stiff epiglottis. ${ }^{8}$ The safety and efficacy of the routine use of fibreoptic intubation techniques in infants has not been prospectively investigated, although multiple case reports describe fibreoptic intubation in selected children. ${ }^{3,9-15}$ Kleeman $e t$ al. used an ultrathin fibreoptic scope directly to intubate the trachea of an infant with the Pierre-Robin syndrome. ${ }^{13}$ Finer et al. used an ultrathin fibreoptic scope to intubate the tracheas of 23 neonates with dysmorphic airways or severe hydrocephalus. ${ }^{14}$ Monrigal et al. used an ultrathin fibreoptic scope to secure the airway in ten infants with dysmorphic features, four of whose tracheas had been previously intubated using a two-staged guide wire technique. ${ }^{15}$ There were no reports of failure in any of these cases.

Anaesthetists who report the use of an ultrathin fibreoptic laryngoscope for intubation of neonates and infants with difficult airway anatomy have remarked on the superiority of this technique to other airway management options. ${ }^{13-15}$ These clinicians commented on the ease of endotracheal tube placement (compared with two-stage fibreoptic observation techniques), decreased 
TABLE III Systolic and diastolic blood pressure and heart rate in rigid and fibreoptic laryngoscopy

\begin{tabular}{|c|c|c|c|c|c|c|c|c|}
\hline Group & $\begin{array}{l}\text { Before } \\
\text { induction }\end{array}$ & $\begin{array}{l}\text { Before } \\
\text { intubation }\end{array}$ & $\begin{array}{l}\text { Afier } \\
\text { intubation }\end{array}$ & Min I & $\operatorname{Min} 2$ & $\operatorname{Min} 3$ & $\operatorname{Min} 4$ & Min 5 \\
\hline \multicolumn{9}{|c|}{ Rigid laryngoscopy $(n=20)$} \\
\hline Systolic BP & $108 \pm 4$ & $94 \pm 2$ & $102 \pm 2^{*}$ & $99 \pm 2^{*}$ & $96 \pm 2$ & $96 \pm 2$ & $92 \pm 2$ & $93 \pm 2$ \\
\hline Diastolic BP & $60 \pm 3$ & $43 \pm 2$ & $50 \pm 3^{*}$ & $46 \pm 2$ & $43 \pm 2$ & $42 \pm 2$ & $41 \pm 2$ & $40 \pm 3$ \\
\hline HR & $168 \pm 7$ & $167 \pm 3$ & $174 \pm 3^{*}$ & $171 \pm 3$ & $169 \pm 3$ & $167 \pm 3$ & $166 \pm 3$ & $165 \pm 3$ \\
\hline \multicolumn{9}{|c|}{ Fibreoptic laryngoscopy $(n=20)$} \\
\hline Systolic BP & $114 \pm 3$ & $98 \pm 3$ & $105 \pm 3^{*}$ & $103 \pm 3$ & $100 \pm 3$ & $98 \pm 3$ & $97 \pm 3$ & $95 \pm 3$ \\
\hline Diastolic BP & $60 \pm 3$ & $42 \pm 1$ & $52 \pm 2^{*}$ & $48 \pm 3$ & $45 \pm 2$ & $43 \pm 2$ & $42 \pm 2$ & $42 \pm 2$ \\
\hline HR & $159 \pm 5$ & $160 \pm 2$ & $169 \pm 2^{*}$ & $165 \pm 2^{*}$ & $162 \pm 2$ & $161 \pm 2$ & $159 \pm 2$ & $158 \pm 2$ \\
\hline
\end{tabular}

Mean \pm SEM.

$* P<0.05$ compared with pre-intubation values.

trauma, and the ability to confirm correct endotracheal tube tip placement visually. ${ }^{13-15}$

The purpose of this study was to determine the safety of the routine use of ultrathin fibreoptic laryngoscopy by experienced practitioners for the placement of endotracheal tubes in infants between 1 and 24 mo of age in order to maintain airway management skills. Documenting safety would justify the routine use of the ultrathin fibreoptic laryngoscope in normal infants to maintain skills needed for management of the difficult infant airway.

It should be noted that we do not advocate the routine use of muscle relaxants in infants with difficult airways; however, to make an accurate comparison of rigid with ultrathin fibreoptic laryngoscopes we elected to use them in all cases. In the case of an actual difficult airway, the ultrathin fibreoptic scope has been utilized successfully using topical alone or topical combined with a ketamine anaesthetic. ${ }^{13,15}$ Also, occasionally, in a child whose trachea is difficult to intubate it may be easy to ventilate the lungs by mask. In this circumstance a muscle relaxant might be used to facilitate fibreoptic intubation as was done in our study.

The principal findings of this study can be summarized as follows: (1) intubation took longer to perform $(P<$ $0.01)$ in the fibreoptic laryngoscopy group $(22.8 \mathrm{sec})$ than in the standard laryngoscopy group (13.6 sec); (2) there was no decrease in $\mathrm{O}_{2}$ SAT in either group; (3) no clinically important airway trauma was observed in either group; (4) there was a small increase in post-intubation HR and increased blood pressure in both groups, but no differences in vital sign changes between study groups. Although these differences were statistically significant, they were not felt to be clinically important.

Few studies have compared fibreoptic intubation with intubation using rigid laryngoscopy. The studies that are available were performed in adults. ${ }^{16-18}$ Smith reported that adult fibreoptic tracheal intubation required approximately $17 \mathrm{sec}$ longer to perform than intubation by rigid laryngoscopy and was associated with a mild increase in BP and HR. ${ }^{16}$ A later study from the same medical centre confirmed these cardiovascular effects. ${ }^{17}$ These findings are similar to our observations. Hawkyard $e t$ al., in contrast, reported a small decrease in mean BP and minimal change in HR with fibreoptic laryngoscopy performed after sedation, compared with a moderate increase in both BP and HR seen with rigid laryngoscopy performed after induction of general anaesthesia. ${ }^{18}$ The time required to accomplish intubation was not reported and the only complication reported of importance was nasal pain in the fibreoptic group.

We conclude that, in experienced hands, fibreoptic intubation using the ultrathin Olympus scope with the methods we described is safe for routine use in the healthy infant 1 to $24 \mathrm{mo}$ of age. Of note, only a minimal amount of practice was necessary to obtain proficiency in the use of this fibreoptic scope by anaesthetists familiar with the use of larger fibreoptic scopes.

\section{Acknowledgement}

We thank Dr. Silas Glisson, Northwestern University, Department of Anesthesia for his guidance in statistical analysis.

\section{References}

1 Benumof $J L$. Management of the difficult adult airway. Anesthesiology 1991; 75: 1087-110.

2 Ovassapian A, Dykes $M H M$. The role of fiber-optic endoscopy in airway management. Seminars in Anesthesia 1987; 6: 93-104.

3 Rucker RW, Silva WJ, Worcester CC. Fiberoptic bronchoscopic nasotracheal intubation in children. Chest 1979; 76: 56-8.

4 Beyer $W H(E d$.$) . Handbook of Tables for Probability and$ 
Statistics, 2nd ed. Cleveland: The Chemical Rubber Co., 1976; 480.

5 Rogers $M C$ (Ed.). Textbook of Pediatric Intensive Care, Vol. 1, 2nd ed. Baltimore: Williams \& Wilkins, 1992; 244.

6 Murphy $P$. A fibre-optic endoscope used for nasal intubation. Anaesthesia 1967; 22: 489-91.

7 Wood RE. Clinical applications of ultrathin flexible bronchoscopes. Pediatr Pulmonol 1985; 1: 244-8.

8 Eckenhoff JE. Some anatomic considerations of the infant larynx influencing endotracheal anesthesia. Anesthesiology 1951; 12: 401-10.

9 Scheller JG, Schulman SR. Fiber-optic bronchoscopic guidance for intubating a neonate with Pierre-Robin syndrome. J Clin Anesth 1991; 3: 45-7.

10 Wilder $R T$, Belani $K G$. Fiberoptic intubation complicated by pulmonary edema in a 12-year-old child with Hurler syndrome. Anesthesiology 1990; 72: 205-7.

11 Berthelsen P, Prytz S, Jacobsen E. Two-stage fiberoptic nasotracheal intubation in infants: a new approach to difficult pediatric intubation. Anesthesiology 1985; 63: 457-8.

12 Alfery $D D$, Ward CF, Harwood IR, Mannino FL. Airway management for a neonate with congenital fusion of the jaws. Anesthesiology 1979; 51: 340-2.

13 Kleeman P-P, Jantzen J-PAH, Bonfils $P$. The ultra-thin bronchoscope in management of the difficult paediatric airway. Can J Anaesth 1987; 34: 606-8.

14 Finer NN, Muzyka D. Flexible endoscopic intubation of the neonate. Pediatr Pulmonol 1992; 12: 48-51.

15 Monrigal JP, Granry JC, LeRolle T, Rod B, Cavellat $M$. Difficult intubation in newborns and infants using an ultra thin fibreoptic bronchoscope. Anesthesiology 1991; 75: A1044.

16 Smith $J E$. Heart rate and arterial pressure changes during fibreoptic tracheal intubation under general anaesthesia. Anaesthesia 1988; 43: 629-32.

17 Smith JE, MacKenzie AA, Scott-Knight VCE. Comparison of two methods of fibrescope-guided tracheal intubation. Br J Anaesth 1991; 66: 546-50.

18 Hawkyard SJ, Morrison A, Doyle LA, Croton RS, Wake $P N$. Attenuating the hypertensive response to laryngoscopy and endotracheal intubation using awake fibreoptic intubation. Acta Anaesthesiol Scand 1992; 36: 1-4. 